\title{
Flash Sterilization: Carefully Measured Haste
}

Ther nis no werkman, what-so-ever he be, that may bothe werke wel and hastily.

The Merchant's Tale Chaucer (1395)

Reliable sterilization of surgical gowns, linens and instruments, implanted devices and innumerable other items essential to medical care is one of the oldest and most basic measures for the prevention of nosocomial infection, dating back to the epochal studies of Pasteur and Koch over a century ago. Precise delineation of the temperature, pressure, and exposure times required for reliable killing of pathogenic microorganisms, including heat-resistant sporulating bacteria, by pressurized steam was one of the major early technologic achievements permitting institutions to carry out reprocessing and sterilization safely.

In the early part of this century, microbiologists and clinicians began to seek further assurances of sterility of reprocessed items, ${ }^{1}$ beyond monitoring the temperature, pressure, and exposure time of the autoclave cycle, and suspensions of bacterial spores came into use as a biological means of monitoring steam sterilization. ${ }^{2,3}$ In the late 1950 s, commercially manufactured biological indicators, consisting of standardized preparations of Bacillus stearothermophilus spores with defined heat-kill characteristics, began to be used in US hospitals.

At present, biological indicators utilizing $B$ stearothermophilus spores for heat sterilizers and Bacillus subtilis var

\footnotetext{
From the Infection Control Department, University of Wisconsin Hospital and Clinics, and the Section of Infectious Diseases, Department of Medicine, University of Wisconsin Medical School, Madison, Wisconsin.

Address reprint requests to Dennis G. Maki, MD, University of Wisconsin Hospital and Clinics, H41574, 600 Highland Avenue, Madison, WI 53792.
}

niger or var globigii spores for ethylene oxide sterilizers, are used by industry and all US hospitals for monitoring sterilization procedures. The Joint Commission on the Accreditation of Hospitals (JCAH), ${ }^{4}$ the Association for Advancement of Medical Instrumentation (AAMI), 5-7 the Association of Operating Room Nurses (AORN), ${ }^{8}$ and the Centers for Disease Control (CDC) ${ }^{9}$ recommend that all hospital steam autoclaves be monitored at least weekly with biological indicators; every load containing implantable objects should be monitored with a spore test: Ethyl: ene oxide sterilizers should also be monitored at least weekly-the JCAH, AAMI, and AORN recommend monitoring every load; all ethylene oxide sterilizer loads containing implantables should be routinely monitored. The JCAH, AORN, and CDC further recommend that sterilizer loads containing implantables or intravascular devices be quarantined until the spore test has been reported as negative.

It is important to recognize that the use of biological indicators does not guarantee sterility, but rather provides an additional mechanism for monitoring the sterilizer cycle, beyond the graphic temperature-pressure record and the physical-chemical indicators: a negative biological indicator test offers further assurance that the sterilizer temperature, pressure, (in the case of ethylene oxide sterilizers, ethylene oxide concentration and humidity), and exposure time were what was intended and as such, it can be inferred that there is a very high probability that all viable microorganisms contaminating items contained in the load were indeed killed.

However, use of biological indicators adds to the costs of reprocessing and sterilization. Moreover, despite United States Pharmacopeia (USP) ${ }^{10}$ and AAMI ${ }^{11}$ standards for their manufacture, a number of reports have documented considerable variability in spore concentrations and par- 
ticularly, quantitative resistance to heat or ethylene oxide killing under defined conditions (D values) of different manufacturers' biological indicators. ${ }^{12-16}$ Clusters of false-positive spore tests have been traced to such variability. ${ }^{17,18} \mathrm{~A}$ positive biological indicator test must prompt immediate evaluation of the sterilizer as well as consideration of whether to issue a recall of remaining items that had been contained in the load and begin follow-up of patients exposed to potentially contaminated items in the load. The expense of striving to retrieve and reprocess items mistakenly thought to have failed sterilization because of false-positive spore tests is obviously considerable.

The margin for allowable error implicit in modern sterilization procedures is also sufficiently large that sterilizer malfunction, as should ideally be identified by an abnormal graphic sterilizer record and chemical indicator tests as well as a positive biological indicator test, is unlikely to result in failure of items contained in the load to be sterilized, especially if the microbial bioburden on reprocessed items has been reduced prior to sterilization by proper cleaning. As a consequence, nosocomial infection, particularly bacterial infection traced to sterilization failure, has been exceedingly rare. Given all of these considerations, the value and particularly the cost-benefit of monitoring sterilization with biological indicators has been questioned in recent years. ${ }^{19-21} \mathrm{Few}$ hospitals in Great Britain and Europe routinely monitor sterilization. ${ }^{19,20}$

But it must be recognized that sporulating bacteria and certain viral pathogens, such as the Jakob-Creutzfeldt agent, ${ }^{22}$ are highly resistant to physical-chemical extremes and could conceivably survive suboptimal sterilizer cycles that should be identified by monitoring with biological indicators; iatrogenic Jakob-Creutzfeldt disease occurring decades later would be exceedingly difficult, if not impossible, to link conclusively to sterilization failure. Moreover, there have been reports, although very rare, of serious bacterial infections ascribed to failure of sterilization procedures in a hospital. ${ }^{23,24}$

Thus, whereas proper reprocessing, wrapping and loading of materials into the sterilizer and meticulous monitoring of the graphic record and chemical indicators continue to be of greatest importance for assuring reliable sterilization of materials in the hospital, 4-9,19-21,25 monitoring with biological indicators can provide an additional quality control mechanism for detecting sterilizer malfunction or improper personnel practices, both with steam and ethylene oxide sterilizers. In a seven-year prospective study of the value of monitoring hospital sterilizers with commercial spore tests, we found that $1.7 \%$ of 7,034 steam loads and $1.2 \%$ of 5,282 ethylene oxide sterilizer loads showed a positive test; probable true sterilizer failure, most often due to identified sterilizer malfunction or personnel error, accounted for $87 \%$ of positive tests of steam autoclaves and $82 \%$ of positive tests with ethylene oxide sterilizers. ${ }^{26}$

In the 1940s and 1950s, the desire for more rapid resterilization of instruments and other items used in surgery prompted studies by Underwood ${ }^{27}$ and Perkins $^{28}$ that delineated parameters for high-speed steam sterilization $\left(132^{\circ} \mathrm{C}\left[270^{\circ} \mathrm{F}\right]\right.$ for three minutes). Initially designed for rapid reprocessing of dropped surgical instruments or special instruments in short supply, highspeed sterilization by the unwrapped method ("flash" sterilization) has come to be performed in most hospitals outside the central supply department in gravity-displacement autoclaves, as compared with the larger prevacuum sterilizers used for conventional full-cycle steam sterilization $\left(121^{\circ} \mathrm{C}\left[250^{\circ} \mathrm{F}\right]\right.$ for 15 minutes $)$ in central supply departments.

We believe that flash sterilization is overused in many US hospitals, most often for convenience, to compensate for inadequate inventories of critical instruments or implantables, or for failure to anticipate need. Many hospitals flash sterilize orthopedic, neurosurgical, and even cardiovascular implantables.

Flash sterilization of implantable objects subjects these critical items, where failure of sterilization has a high probability of disastrous clinical consequences, to a form of heat sterilization with a lower margin of safety. Moreover, immediate use of flash sterilized implantables precludes the use of biological indicators and quarantine that allow a higher level of confidence that the item was truly subjected to the optimal conditions necessary for reliable sterilization. Flash sterilization of implantables should be assiduously avoided..$^{5-9}$

Common sense dictates that reprocessing, decontamination, and sterilization procedures be centralized as much as possible to ensure consistency and maximal quality control. Yet, flash sterilization in most clinical facilities is done outside the central supply department with its trained personnel: in the operating room, the labordelivery area, the emergency department, or in outpatient clinics. Moreover, flash sterilization is often used in health care facilities outside of hospitals, such as surgicenters. In all of these settings, personnel with responsibility for sterilization procedures often have received little formal training in the proper use of the equipment and have little understanding of the fundamentals of steam sterilization. Record keeping is frequently scant, particularly with respect to items contained in each load, maintenance, and quality control monitoring.

One of the most serious outbreaks of infection traced to sterilizer failure occurred in one hospital when failure of flash sterilization of implantable devices used for neurosurgical shunting procedures resulted in six cases of $P$ seudomonas aeruginosa meningitis or intraabdominal infection. ${ }^{24}$

It would seem that the use of biological indicators as an adjunctive means for monitoring sterilization would be of greatest importance with flash sterilizers. Little has been published, however, on the use of biological indicators in flash sterilization. Perkins et $\mathrm{a}^{29}$ were the first to point out that the standard commercial biological indicators used for monitoring full-cycle steam autoclaves $\left(121^{\circ} \mathrm{C}\left[250^{\circ} \mathrm{F}\right]\right.$ for 15 minutes) might be inadequate when used for monitoring high-speed (flash) sterilizers; a widely used self-contained indicator gave uniformly false-positive results when tested in a standard three-minute flash cycle $\left(132^{\circ} \mathrm{C}\left[270^{\circ} \mathrm{F}\right]\right)$, whereas a paper spore-strip gave more reliable results. In contrast, Epstein et al encountered 
frequent false-positive tests with the same spore-strip indicator when used for monitoring flash sterilizers in actual use. ${ }^{18}$

Biological indicators specifically designed for monitoring flash sterilization are now available. Except for a small study by Tornello et al, ${ }^{30}$ which prompted complaints from several manufacturers, ${ }^{31}$ and an analysis of four indicator systems published by one of the manufacturers, ${ }^{32}$ evaluations of commercial biological indicators designated for monitoring flash sterilizers have not been published.

The report by Kotilainen and Gantz in this issue of Infection Control (pp 311-316) evaluates three commercial biological indicators, two specifically designated for monitoring flash sterilizers. ${ }^{33}$ The study was not a clinical evaluation, but rather an analysis of the performance characteristics (kill/survival ratios) of three marketed indicators under controlled conditions. Their analysis points out that one of the indicators may not be sufficiently resistant to heat killing to reliably detect conditions likely to result in flash sterilization failure, that one was technically difficult to use, and that the third was both easy to use and exhibited desirable performance characteristics. There was a considerable and surprising range in the concentration of $B$ stearothermophilus spores in the three commercial systems tested. The major shortcoming of this study was the small number of samples tested in each group. Commercially produced indicators for flash sterilizers should ideally now be tested in parallel in actual clinical use in large trials to ascertain relative efficiency in detecting sterilization failure.

These studies ${ }^{30,32,33}$ point up the need for the development of standards for the manufacture of biological indicators designated for monitoring flash sterilizers, similar to the $\mathrm{USP}^{10}$ and $\mathrm{AAMI}^{11}$ standards guiding the manufacture of biological indicators for full-cycle steam sterilizers.

AAMI has provided a valuable service by recently publishing detailed recommendations for flash sterilization procedures in hospitals. ${ }^{7}$ Salient points from this report include the following (emphasis added):

- "Steam sterilization by the unwrapped (flash) method is not recommended if time permits the use of the preferred, wrapped conventional method."

- "The use of flash sterilization should be restricted to unplanned or emergency situations."

- "Implantables should never be sterilized by the unwrapped method."

- "It is critical that the equipment used for steam sterilization by the unwrapped method meet all the standards for other steam sterilizers used in health care facilities."

- "Ideally, the decontamination/preparation areas should be physically separated from the sterilization area by means of partitions or walls. Spatial separation may be satisfactory, however, if compensated for by good work flow patterns, air flow characteristics, and work practices."

- "All preparation and sterilization of items by the unwrapped method must be performed under competent supervision."
- "Personnel responsible for steam sterilization by the flash method must have demonstrated comprehensive knowledge and competence in all aspects of steam sterilization."

- Instruments that have been soiled must be carefully cleaned prior to resterilization.

- "To achieve sterility, high-temperature saturated steam must come into direct contact with all surfaces of all items." Items must be properly loaded on perforated or mesh-bottom trays.

- The recommended minimum exposure time and temperature for nonporous loads, such as those containing metal instruments only, both for gravity-displacement sterilizers and prevacuum sterilizers, is three minutes at or above $132^{\circ} \mathrm{C}\left(270^{\circ} \mathrm{F}\right)$. The recommended minimums when porous items are in the load (eg, linens, rubber or plastic items, items with lumens) are at least ten minutes at or above $132^{\circ} \mathrm{C}$ $\left(270^{\circ} \mathrm{F}\right)$ for gravity-displacement sterilizers and at least four minutes at or above $132^{\circ} \mathrm{C}\left(270^{\circ} \mathrm{F}\right)$ for prevacuum sterilizers. Sterilization of special instruments and devices may require different exposure times; the manufacturers' instructions should be followed.

- "Since the sterilized items will not be protected by packaging after sterilization, special care must be taken to avoid contamination. The sterilization area should be located immediately adjacent to, or be a part of, the area where the items will be used in patient care."

- Flash sterilizers deserve the same quality care and maintenance given to conventional full-cycle steam sterilizers used in central supply departments, and must be inspected and cleaned in accordance with the manufacturers' written instructions. Pressure and temperature gauges, timers, and controls should be periodically calibrated, and accurate and complete maintenance records kept for each sterilizer.

Quality control, including careful records for each sterilizer load, and the results of biologic monitoring as well as the results of Bowie-Dick-type testing should be documented and recorded for each sterilizer.

- At the end of each cycle, the operator must examine the time/temperature chart to verify that the correct temperature has been attained and maintained for the correct exposure time.

- "A chemical indicator should be used in each tray or container being processed."

- "A biologic-indicator test should be used to check each sterilizer at least once a week."

- "Only biological indicators which have been specifically validated for monitoring 'flash sterilization' should be selected for this purpose."

- "One or more biological indicators and a chemical indicator should be placed in a perforated or meshbottom surgical tray of appropriate size for the sterilizer to be tested. The test tray is placed on the bottom shelf of an otherwise empty sterilizer. One additional indicator from the lot used for testing should be left unexposed to the sterilant, incubated and treated as a positive control." 
- A positive biological indicator test should be assumed to be a "true" positive until proven otherwise, and should mandate immediate retesting of the same sterilizer with biological indicators. "Until the results of retesting are satisfactory, other quality control information, including historical data on sterilizer performance, should be reexamined and a decision made on whether to quarantine the sterilizer."

\section{Haste and hurry are very different things. \\ Letiers \\ Lord Chesterton (1777)}

\section{REFERENCES}

1. Dandy WE: The importance of more adequate sterilization processes in hospitals. Bull Am Coll Surg 1932; 16:11-14

2. Bigelow WD, Esty JR: The thermal death-point in relation to time of typical thermophilic organisms. J Infect Dis 1920; 27:602-617.

3. Williams LB: The heat resistance of bacterial spores. J Infect Dis 1929; 44:421-465.

4. Joint Commission on the Accreditation of Hospitals: Accreditation Manual for Hospitals 1986 Edition. Chicago, American Hospital Association, 1986, pp 76-78.

5. Good Hospital Practice: Steam Sterilization and Sterility Assurance. Arlington, Association for the Advancement of Medical Instrumentation, 1980.

6. Ethylene Oxide Sterilization: A Guide for Hospital Personnel. Arlington, Association for the Advancement of Medical Instrumentation, 1976.

7. Good Hospital Practice: Steam Sterilization Using the Unurapped Method (Flash Sterilization), September 1985 revision. Arlington, Association for the Advancement of Medical Instumentation, 1985 .

8. Proposed recommended practices: Sterilization and disinfection. AORN J $1985 ; 42: 734-754$.

9. Garner JS, Favero MS: Guideline for handwashing and hospital environmental control, 1985, in Guidelines for the Prevention and Control of Nosocomial Infections. Atlanta, Centers for Disease Control, Government Printing Office, 1985, pp 10-13.

10. USP: The Pharmacopeia of the United States of America XX. US Pharmacopeial Convention, Rockville, MD, Mack Publishing Co, 1980.

11. Biological Indicators for Safurated Steam Sterilization Processes in Health Care Fucilities. Arlington, Association for the Advancement of Medical Institutions, 1985.

12. Macek TJ: Biological indicators. A USP review. Bull Parenter Drug Assoc 1972; 26:18-25.
13. Mayernick JJ: Biological indicators for steam sterilization: A USP collaborative study. Bull Parenter Drug Assoc 1972; 26:205-211.

14. Gillis JR: Biological indicators for steam sterilization process monitoring. Bull Parenter Drug Assoc 1975; 29:111-121.

15. Reich RR: Influence of environmental storage relative humidity on biological indicator resistance, viability and moisture content. Appl Environ Microbiol 1982; 43:609-614

16. Hodges NA: A comparison of heat resistance of commercially available $B$ stearothermophilus spore preparations. J Pharm Pharmacol 1982; 24:259-260.

17. Maki DG, Alvarado C, Hassemer C: False-positive results of spore tests in ethylene oxide sterilizers-Wisconsin. MMWR 1981; 30:238-240.

18. Epstein BI, Latimer JM, Matsen JM, et al: False-positive spore strip sterility tests with steam sterilization. Am J Infect Control 1983; 11:71-73.

19. Anonymous: Sterilization? editorial. J Hosp Infect 1981; 2:289-290.

20. Greene VW: Control of sterilisation process, in Russell AD, Hugo WB, Ayliffe GAJ (eds): Principles and Practice of Disinfection, Preservation and Sterilisation. Oxford, Blackwell Scientific Publications, 1982.

21. Joslyn L: Sterilization by heat, in Black SS (ed): Disinfection, Sterilization and Preservation, ed 3. Philadelphia, Lea and Febiger. 1983.

22. Gajdusek DC, Gibbs CJ, Asher DM, et al: Precautions in medical care of, and in handling materials from, patients with transmissible virus dementia (Creutzeldt-Jakob disease). N Engl J Med 1977; 297:1253-1258.

23. Sevitt S: Source of two hospital-infected cases of tetanus. Lancet 1949; $2: 1075$.

24. Ho JL, Highsmith AK, Wong ES, et al: Common-source Pseudomonas aeruginosa infection in neurosurgery. Proceedings and Abstracts of the Annual Meeting of the American Society for Microbiology. Washington, DC, American Society for Microbiology, 1981.

25. Perkins JJ: Principles and Methods of Sterilization in Health Sciences, ed 2. Springfield, IL, Charles Thomas Publishers, 1969.

26. Maki DG, Hassemer C, Alvarado C: Prospective study of the value of monitoring hospital sterilizers with biologic indicators. Proceedings and Abstracts of the 25th Interscience Conference on Antimicrobial Agents and Chemotherapy, Minneapolis. Washington, DC, American Society for Microbiology, 1985

27. Underwood WB: A Textbook of Sterilization, ed 2. Chicago, RR Donnelley and Sons Co, 1942, pp 91-93.

28. Perkins JJ: Bacteriological and surgical sterilization by heat, in Reddish GF (ed): Antiseptics. Disinfectants, Fungicides and Chemical and Physical Sterilization. Philadelphia, Lea and Febiger, 1954, p 672.

29. Perkins RE, Bodman HA, Kundsin RB, et al: Monitoring steam sterilization of surgical instruments: A dilemma. Appl Environ Microbiol 1981; 42(2):383-384.

30. Tornello JD: Flash sterilization: Evaluating biological indicators. AORN J 1986; 43:1289-1294.

31. McCormick PJ, Griffith DB: Flash sterilization: Article creates controversy. $A O R N$ J 1986; 44:908-909.

32. Reich RR, Fitzpatrick BG: Flash sterilization.J Hosp Supply Processing Distribution May/June 1985; 60-63.

33. Kotilainen HR, Gantz NM: An evaluation of three biological indicator systems in flash sterilization. Infect Control 1987; 8:311-316. 